\title{
Real-World Persistence with Tocilizumab Compared to Other Subcutaneous Biologic Disease-Modifying Antirheumatic Drugs Among Patients with Rheumatoid Arthritis Switching from Another Biologic
}

Jennie H. Best · Steven C. Vlad · Lenore Tominna $\cdot$ Ibrahim Abbass

Received: February 7, 2020 / Published online: March 29, 2020

(C) The Author(s) 2020

\section{ABSTRACT}

Introduction: In patients with rheumatoid arthritis (RA) who have an inadequate response to or intolerance of their first biologic diseasemodifying antirheumatic drug (bDMARD), guidelines recommend switching to a different biologic class. The objective of this study was to compare persistence with subcutaneous (SC) tocilizumab to persistence with other SC bDMARDs when these drugs are used as subsequent-line therapy in RA patients who previously received $\geq 1$ bDMARD.

Methods: RA patients in a US administrative claims database who initiated a second- or subsequent-line SC bDMARD between January 1, 2012 and June 30, 2017 (initiation date $=$ index date) were included. Persistence was defined as the number of days between the bDMARD initiation date and (1) the last supplied day of medication fill (primary) or (2) the day on which the patient switched or there was a gap in treatment of $>90$ days (secondary).

Digital Features To view digital features for this article go to: https://doi.org/10.6084/m9.figshare.11974503.

J. H. Best $(\varangle) \cdot$ L. Tominna - I. Abbass

Genentech, Inc., South San Francisco, CA, USA

e-mail: best.jennie@gene.com

S. C. Vlad

Department of Rheumatology, Tufts Medical

Center, Boston, MA, USA
Parametric survival models utilizing an exponential distribution with a robust variance estimator were used to compare persistence with tocilizumab to persistence with other bDMARDs.

Results: A total of 10,301 patients with 12,704 bDMARD episodes were included. Patients receiving tocilizumab had a significantly higher adjusted median (95\% CI) number of days of primary persistence [333 (311-356)] than those receiving adalimumab [280 (268-293); $P<0.001], \quad$ certolizumab $[262 \quad(241-284)$; $P<0.001]$, and etanercept [289 (274-304); $P=0.001]$, and a similar persistence to those receiving abatacept [320 (305-335); $P=0.327]$ and golimumab [304 (274-333); $P=0.122]$.

Conclusion: Among patients with RA who had previously received $\geq 1$ bDMARD, tocilizumabtreated patients exhibited a similar or significantly better biologic persistence than those receiving other bDMARDs.

Keywords: Biologic; Persistence; Real-world; Rheumatoid arthritis; Tocilizumab 


\section{Key Summary Points}

\section{Why carry out this study?}

In patients with rheumatoid arthritis (RA) who have an inadequate response to or intolerance of their first biologic diseasemodifying antirheumatic drug (bDMARD), current guidelines recommend switching to a different biologic class.

The objective of this study was to compare persistence with subcutaneous (SC) tocilizumab to persistence with other SC bDMARDs when these drugs are used as subsequent-line therapy in RA patients who previously received first-line bDMARD(s).

\section{What was learned from this study?}

Among patients with RA who previously received $\geq 1$ bDMARD, tocilizumabtreated patients exhibited similar or significantly better biologic persistence than those receiving other bDMARDs.

This study, which involved a large number of second- or subsequent-line SC bDMARD episodes in patients with RA across the United States, provides valuable real-world information and adds to existing data on persistence with bDMARDs.

\section{INTRODUCTION}

Rheumatoid arthritis (RA) is a chronic, progressive autoimmune disease characterized by joint swelling, stiffness, and pain and synovial inflammation, which can lead to permanent joint damage and disability if left untreated $[1,2]$. The goal of RA treatment is to achieve sustained remission or low disease activity based on shared decision-making between the patient and rheumatologist taking into account disease activity, prognostic factors, and comorbidities [2-4]. The American College of Rheumatology (ACR) and European League
Against Rheumatism (EULAR) guidelines recommend that RA should initially be treated with conventional synthetic disease-modifying antirheumatic drugs (csDMARDs), such as methotrexate $[2,3]$. If patients have an inadequate response to csDMARDs, the addition of either a second csDMARD, a biologic DMARD (bDMARD), or a targeted synthetic DMARD is recommended [2, 3].

Although bDMARDs are effective for many patients with RA, switching to another biologic may sometimes be necessary because of treatment-related adverse events or a failure to achieve adequate disease control [5]. Approximately $30-40 \%$ of patients have an inadequate response to csDMARDs and first-line bDMARDs, most commonly tumor necrosis factor inhibitors (TNFis) [6-8]. In addition, patients receiving bDMARDs may experience a loss of response to treatment over time [9]. In patients with RA who have an inadequate response to or are intolerant of their first bDMARD, guidelines recommend switching to a different biologic class or a targeted synthetic DMARD [2, 3]. Understanding persistence with subsequent-line biologic therapies is important, as it can help to guide rheumatologists and patients in choosing an appropriate therapy after an inadequate response to or intolerance of first-line biologics.

Approved biologics for use in patients with RA have different mechanisms of action, and although there is evidence that supports switching to a biologic with a different mechanism of action, switching to another TNFi is more common in clinical practice $[10,11]$. However, the ACR guidelines recommend switching to a nonTNFi after a first-line TNFi failure [2]; additionally, treatment patterns of switching to a bDMARD with a different mechanism of action in patients in whom a first-line bDMARD has failed are increasing. If a patient has an inadequate response to a second bDMARD, multiple guidelines recommend that they should be switched to a biologic with a different mechanism of action $[2,3]$.

Currently available subcutaneous (SC) bDMARDs include TNFis (adalimumab, certolizumab, etanercept, and golimumab), abatacept (a T-cell costimulation inhibitor), interleukin (IL)-6 receptor blockers (tocilizumab and sarilumab), and the IL-1 receptor 
antagonist (anakinra). Treatment persistence has been associated with improved outcomes in patients with RA [12]. However, real-world studies of persistence with SC bDMARDs and comparative information on persistence with SC bDMARDs among patients with RA who are not biologic naïve are limited. The objective of this study was to compare persistence with SCadministered tocilizumab to persistence with other SC bDMARDs when these drugs were used as subsequent-line therapy in RA patients who previously responded inadequately to or were intolerant of first-line bDMARDs.

\section{METHODS}

\section{Data Source and Patient Population}

This US-based retrospective observational study used medical claims data from the IBM $^{\circledR}$ Mar$\operatorname{ketScan}^{\circledR}$ Commercial and Medicare Supplemental Databases, which provide detailed costs, use, and outcomes data for healthcare services performed in both inpatient and outpatient settings. Adult patients (aged 18-89 years) with an International Classification of Diseases, Ninth Revision, Clinical Modification (ICD-9-CM) or ICD-10-CM diagnosis of RA who initiated a SC bDMARD between January 2, 2012 and June 30, 2017 were identified. The index date was defined as the date of SC bDMARD initiation.

Patients were included if they were continuously enrolled in a commercial or Medicare plan for $\geq 6$ months before and $\geq 3$ months after the index date; had received any prior bDMARD, including those not evaluated in this analysis; and did not have other autoimmune conditions during the study period, including ankylosing spondylitis, Crohn's disease, ulcerative colitis, polyarteritis nodosa, granulomatosis with polyangiitis, systemic lupus erythematosus, nonHodgkin's lymphoma, plaque psoriasis, psoriatic arthritis, and juvenile idiopathic arthritis.

This retrospective, observational analysis used only de-identified patient records and did not include the collection, use, or transmittal of individually identifiable data; therefore, institutional review board approval to conduct this study was not necessary.

\section{Covariates}

Factors evaluated for persistence included age, sex, geographic region, health plan type, Elixhauser Comorbidity Index (ECI) score [13-15], initial bDMARD, line of biologic therapy (e.g., second, third, etc.), and year of starting the bDMARD. Patients' comorbidities, as identified by ECI, were carried forward from prior treatment episodes if the patients had $\geq 1$ episode.

\section{Outcomes}

Primary bDMARD persistence was defined as the number of days between the initiation date and the last supplied day of medication fill. Patients who had a gap in therapy (e.g., during a period of remission) and then restarted on the same bDMARD were considered to be persistent; patients who switched therapy were considered nonpersistent [16]. Secondary persistence was defined as the period of time that patients received bDMARDs until they switched or had a gap in treatment of $>90$ days [16]. Patients who switched to a different bDMARD were included as a separate episode (i.e., patients could have multiple episodes due to switching to a different biologic as a third- or subsequent-line therapy). For patients who had a gap in treatment of $>90$ days and then restarted the same bDMARD, only the episode prior to the 90-day gap was included in the analysis.

\section{Statistical Analysis}

Analysis of variance and $\chi^{2}$ tests were used to compare demographic and clinical characteristics between bDMARD episodes. Parametric survival models utilizing an exponential distribution with a robust variance estimator were used to compare outcomes with tocilizumab to those with other bDMARDs, adjusting for differences in baseline characteristics and comorbidities over time prior to initiating subsequent bDMARDs and accounting for correlation among different bDMARD episodes. Hazard ratios for discontinuation were derived from the survival models after adjusting for patients' baseline demographics, lines of therapy, and episode-specific comorbidities. 
Patients who left the database (e.g., patients who died or switched to a health plan outside of the database) were censored.

\section{RESULTS}

\section{Demographics and Baseline Characteristics}

Overall, 10,301 patients with 12,704 bDMARD episodes were included (Fig. 1). The most common bDMARD episode was adalimumab $(n=3599)$, followed by abatacept $(n=2988)$, etanercept $(n=2760)$, tocilizumab $(n=1630)$, golimumab $(n=745)$, and certolizumab pegol $(n=982)$. Most patients were female (78.9-82.2\%), and mean age ranged from 51.0 to 53.2 years (Table 1 ). Mean [SD] ECI scores were significantly higher $(P<0.001)$ in patients initiating tocilizumab (2.8 [2.3]) than in those receiving abatacept (2.5 [2.2]), adalimumab (2.5 [2.1]), certolizumab pegol (2.4 [2.0]), etanercept (2.4 [2.0]), or golimumab (2.4 [2.2]) (Table 1).

\section{Outcomes}

Tocilizumab was the least frequently used second-line bDMARD and the most frequently used third-, fourth-, and fifth-line bDMARD (Fig. 2). The adjusted median (95\% CI) number

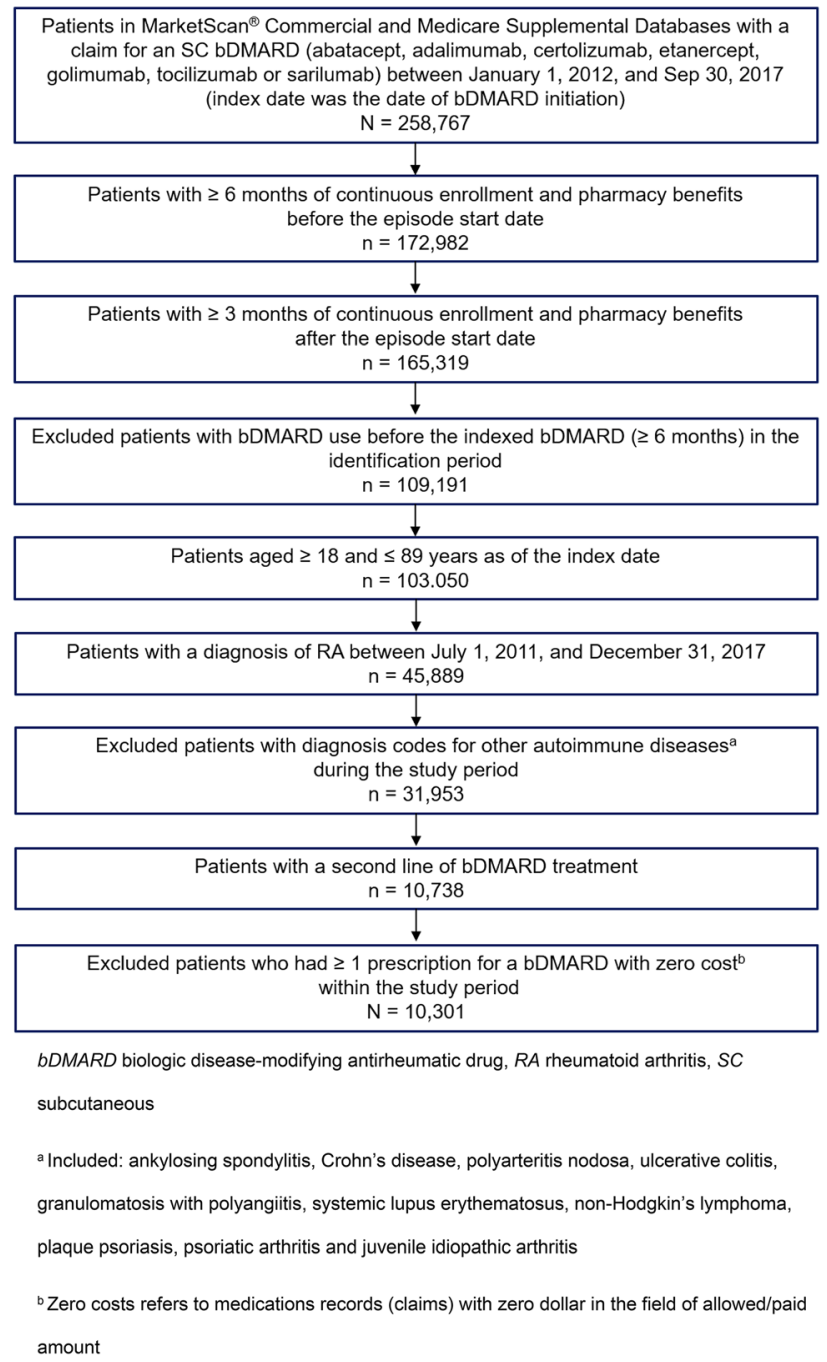

Fig. 1 Patient attrition 
Table 1 Demographics and characteristics

\begin{tabular}{|c|c|c|c|c|c|c|c|}
\hline Variable & $\begin{array}{l}\text { Abatacept } \\
n=2988\end{array}$ & $\begin{array}{l}\text { Adalimumab } \\
n=3599\end{array}$ & $\begin{array}{l}\text { Certolizumab } \\
\text { pegol } \\
n=982\end{array}$ & $\begin{array}{l}\text { Etanercept } \\
n=2760\end{array}$ & $\begin{array}{l}\text { Golimumab } \\
n=745\end{array}$ & $\begin{array}{l}\text { Tocilizumab } \\
n=1630\end{array}$ & $P$ value \\
\hline Age, mean (SD) & $53.2(11.0)$ & $52.7(11.3)$ & $51.0(11.0)$ & $52.5(10.9)$ & $52.1(11.2)$ & $52.7(10.6)$ & $<0.001$ \\
\hline Female, $n(\%)$ & $2446(81.9)$ & $2838(78.9)$ & $807(82.2)$ & $2206(79.9)$ & $610(81.9)$ & $1325(81.3)$ & 0.018 \\
\hline \multicolumn{8}{|c|}{ Health plan type, $n(\%)$} \\
\hline $\mathrm{HMO}$ & $269(9.00)$ & 338 (9.39) & $81(8.25)$ & $252(9.13)$ & $67(8.99)$ & $117(7.18)$ & 0.169 \\
\hline $\mathrm{PPO}$ & $2017(67.5)$ & $2391(66.4)$ & $692(70.5)$ & $1878(68.0)$ & $500(67.1)$ & $1122(68.8)$ & 0.196 \\
\hline Other & $702(23.5)$ & $870(24.2)$ & $209(21.3)$ & $630(22.8)$ & $178(23.9)$ & $391(24.0)$ & 0.472 \\
\hline \multicolumn{8}{|l|}{ US region, $n(\%)$} \\
\hline Northeast & $539(18.0)$ & $620(17.2)$ & $131(13.3)$ & $443(16.1)$ & $136(18.3)$ & $271(16.6)$ & 0.013 \\
\hline South & $1271(42.5)$ & $1564(43.5)$ & $519(52.9)$ & $1327(48.1)$ & $292(39.2)$ & $735(45.1)$ & 0 \\
\hline North Central & $616(20.6)$ & $737(20.5)$ & $157(16.0)$ & $496(18.0)$ & $146(19.6)$ & $307(18.8)$ & 0.005 \\
\hline West & $535(17.9)$ & $631(17.5)$ & $170(17.3)$ & $467(16.9)$ & $152(20.4)$ & $292(17.9)$ & 0.392 \\
\hline Unknown & $27(0.9)$ & $47(1.3)$ & $5(0.5)$ & $27(1.0)$ & $19(2.6)$ & $25(1.5)$ & 0.001 \\
\hline $\begin{array}{l}\text { ECI score, mean } \\
(\mathrm{SD})\end{array}$ & $2.5(2.2)$ & $2.5(2.1)$ & $2.4(2.0)$ & $2.4(2.0)$ & $2.4(2.2)$ & $2.8(2.3)$ & $<0.001$ \\
\hline \multicolumn{8}{|c|}{ Comorbidities, $n(\%)$} \\
\hline $\begin{array}{l}\text { Chronic } \\
\text { pulmonary } \\
\text { disease }\end{array}$ & $486(16.3)$ & $503(14.0)$ & $126(12.8)$ & $386(14.0)$ & $118(15.8)$ & $284(17.4)$ & 0.001 \\
\hline $\begin{array}{l}\text { Deficiency } \\
\text { anemias }\end{array}$ & $426(14.3)$ & $448(12.4)$ & $131(13.3)$ & $369(13.4)$ & $98(13.2)$ & $251(15.4)$ & 0.077 \\
\hline Depression & $279(9.34)$ & $371(10.3)$ & $80(8.1)$ & $265(9.6)$ & $65(8.7)$ & $175(10.7)$ & 0.185 \\
\hline $\begin{array}{l}\text { Diabetes without } \\
\text { chronic } \\
\text { complications }\end{array}$ & $379(12.7)$ & $446(12.4)$ & $94(9.6)$ & $304(11.0)$ & $87(11.7)$ & $202(12.4)$ & 0.072 \\
\hline $\begin{array}{l}\text { Fluid and } \\
\text { electrolyte } \\
\text { disorders }\end{array}$ & $233(7.8)$ & $232(6.4)$ & $74(7.5)$ & $187(6.8)$ & $51(6.8)$ & $130(8.0)$ & 0.211 \\
\hline Hypothyroidism & $513(17.2)$ & $575(16.0)$ & $161(16.4)$ & $458(16.6)$ & $117(15.7)$ & $327(20.1)$ & 0.010 \\
\hline Liver disease & $149(5.0)$ & $154(4.3)$ & $50(5.1)$ & $125(4.5)$ & $30(4.0)$ & $82(5.0)$ & 0.613 \\
\hline Obesity & $487(16.3)$ & $613(17.0)$ & $180(18.3)$ & $470(17.0)$ & $116(15.6)$ & $332(20.4)$ & 0.009 \\
\hline Hypertension & $1070(35.8)$ & $1316(36.6)$ & $346(35.2)$ & $978(35.4)$ & $269(36.1)$ & $638(39.1)$ & 0.184 \\
\hline $\begin{array}{l}\mathrm{RA} / \text { collagen } \\
\text { vascular disease }\end{array}$ & $2273(76.1)$ & $2731(75.9)$ & $765(77.9)$ & $2071(75.0)$ & $570(76.5)$ & $1342(82.3)$ & $<0.001$ \\
\hline Valvular disease & $130(4.4)$ & $131(3.6)$ & $40(4.1)$ & $93(3.4)$ & $28(3.8)$ & $81(5.0)$ & 0.103 \\
\hline
\end{tabular}

ECI Elixhauser Comorbidity Index, HMO health maintenance organization, PPO preferred provider organization, $R A$ rheumatoid arthritis

${ }^{a} P<0.05$ indicates a statistically significant difference among therapies

of days of primary persistence for tocilizumab [333 (311-356)] was significantly higher than those for adalimumab [280 (268-293);
$P<0.001], \quad$ certolizumab $[262 \quad(241-284)$; $P<0.001]$, and etanercept [289 (274-304); $P=0.001]$, and similar to those for abatacept 


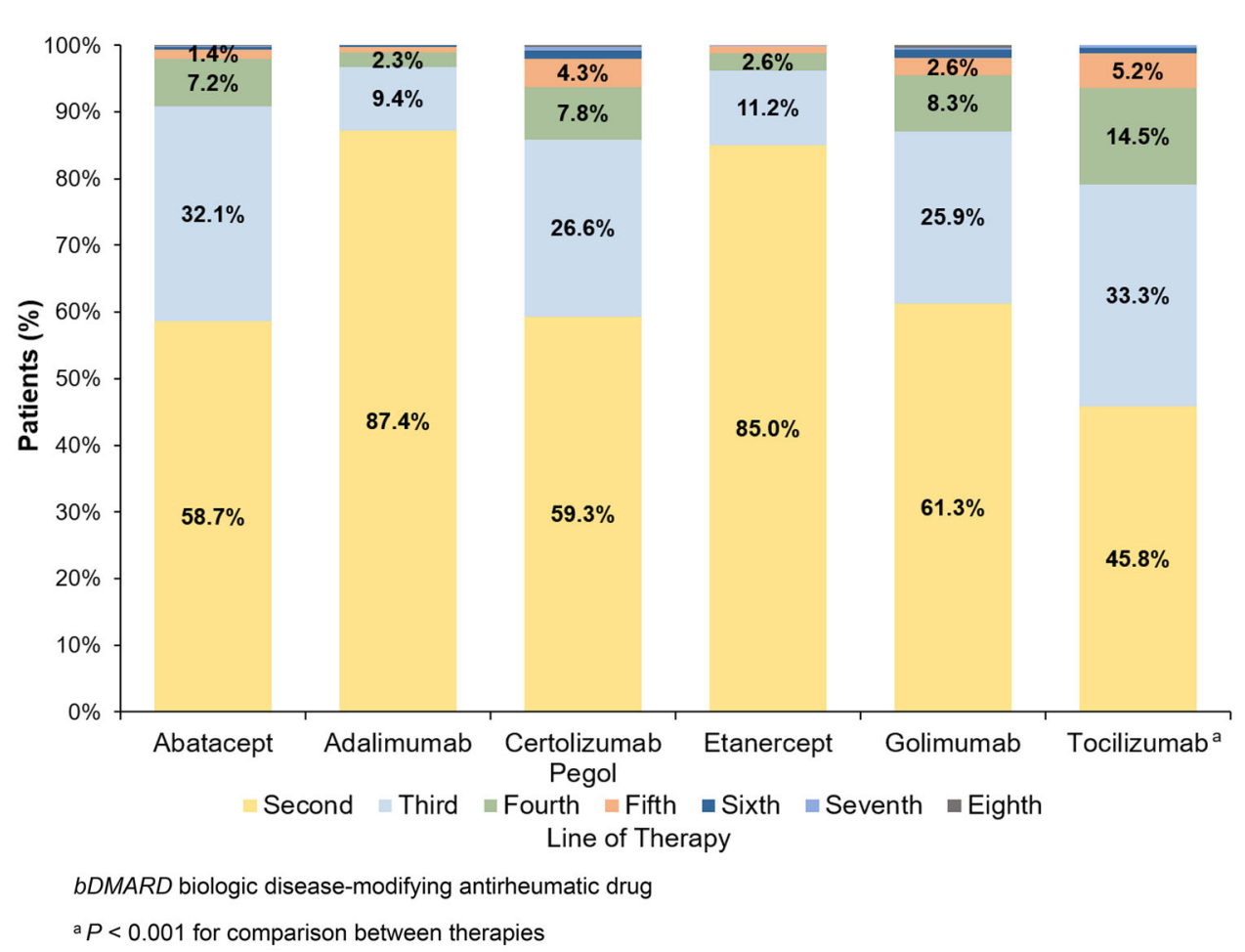

Fig. 2 Lines of bDMARD therapy by biologic

[320 (305-335); $P=0.327$ ] and golimumab [304 (274-333); $P=0.122$ ] (Fig. 3). The adjusted median $(95 \% \mathrm{CI})$ number of days of secondary persistence for tocilizumab [315 (292-337)] was significantly higher than those for adalimumab [265 (253-276); $P<0.001$ ], certolizumab pegol [253 (231-275); $P<0.001]$, and etanercept [272 (257-286); $P=0.001]$, and similar to those for abatacept [306 (291-321); $P=0.545$ ] and golimumab [284 (257-311); $P=0.092$ ] (Fig. 4). After adjusting for patients' baseline demographics, lines of therapy, and episode-specific comorbidities, adalimumab, certolizumab pegol, and etanercept had significantly higher likelihoods of discontinuation than tocilizumab (Tables 2, 3).

Among the patients who received tocilizumab for $\geq 12$ months, $45 \%$ initiated tocilizumab administered every other week (q2w) and $55 \%$ initiated tocilizumab weekly (qw). Of the 347 patients who initiated $\mathrm{q} 2 \mathrm{w}$ tocilizumab, $32.8 \%$ switched to qw dosing over the 12-month follow-up; the mean time to switch was 177 days. After 12 months of follow-up, approximately $68.3 \%$ of patients were receiving qw dosing and $31.7 \%$ were receiving q2w dosing.

\section{DISCUSSION}

In this large US claims-based analysis, persistence with tocilizumab as a second- or subsequent-line bDMARD in patients with RA was found to be similar to or significantly longer than persistence with other bDMARDs. These results are consistent with registry studies showing increased persistence with tocilizumab compared to persistence with TNFis in patients who had an inadequate response to a first-line TNFi [17-19]. Although the present study did not evaluate the reasons for patients switching or discontinuing bDMARD therapy, previous studies have shown that multiple factors are both positively and negatively associated with persistence, including age, sex, and race, as well as disease activity, comorbidities, concurrent use of methotrexate, and therapy-management programs [20]. 


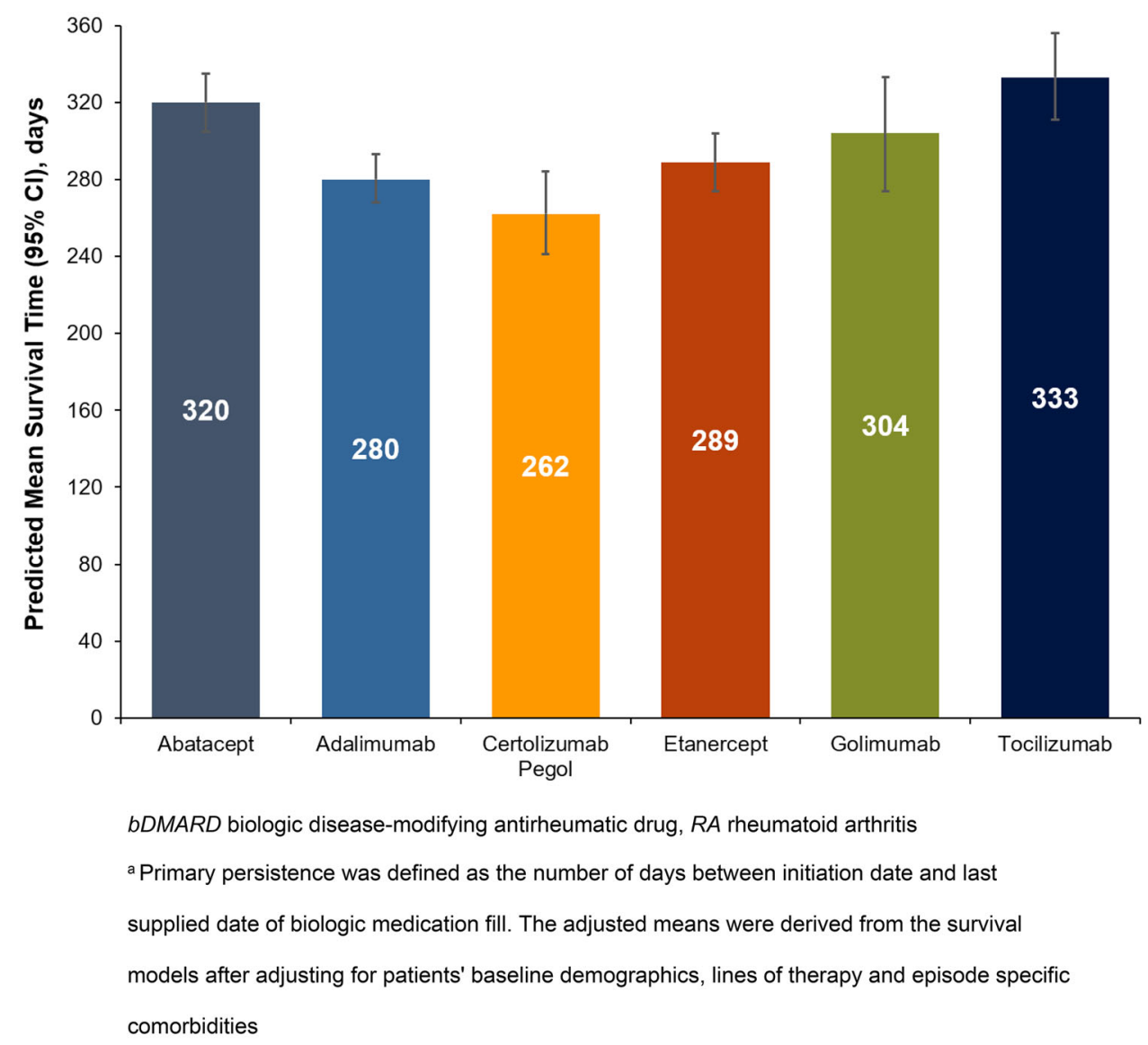

Fig. 3 Adjusted mean primary persistence with bDMARDs among patients with $\mathrm{RA}^{\mathrm{a}}$

The intravenous and SC formulations of tocilizumab have been shown to be safe and effective treatments for patients with RA who are bDMARD naïve and for those with prior exposure to bDMARDs, either as a monotherapy or in combination with csDMARDs [21-25]. As shown in the present study, patients (particularly those treated with tocilizumab) may receive third, fourth, or greater lines of biologic therapy. Frequent switching of biologic therapy can make longer-term management of RA more challenging (e.g., management by payers requiring step therapy) and result in greater costs [26]. Studies have shown that switching from a TNFi to a biologic with a different mechanism of action can be more effective (e.g., higher persistence, improved clinical outcomes) than switching to another TNFi [11, 27-32]. Results from the present study also suggest that for patients who have an inadequate response to their first biologic, switching to one with a different mechanism of action may be more effective than switching to another biologic with the same mechanism of action.

Lower costs have been reported in patients who switched to a bDMARD with a different mechanism of action [28]. Another study reported higher direct costs but lower indirect costs in patients who switched from a first-line TNFi to a bDMARD with a different mechanism of action than in those who switched to another TNFi [33]. For patients weighing $<100 \mathrm{~kg}$, tocilizumab SC is initiated $\mathrm{q} 2 \mathrm{w}$, followed by an increase to qw based on clinical response; for patients weighing $>100 \mathrm{~kg}$, SC tocilizumab is initiated qw [34]. In the present study, 33\% of patients increased tocilizumab dosing from q2w to qw. These results are consistent with a longterm study of SC tocilizumab which showed that $23 \%$ of patients who initiated SC TCZ q2w injections switched to qw within 2 years; in the patients who switched to qw dosing, 


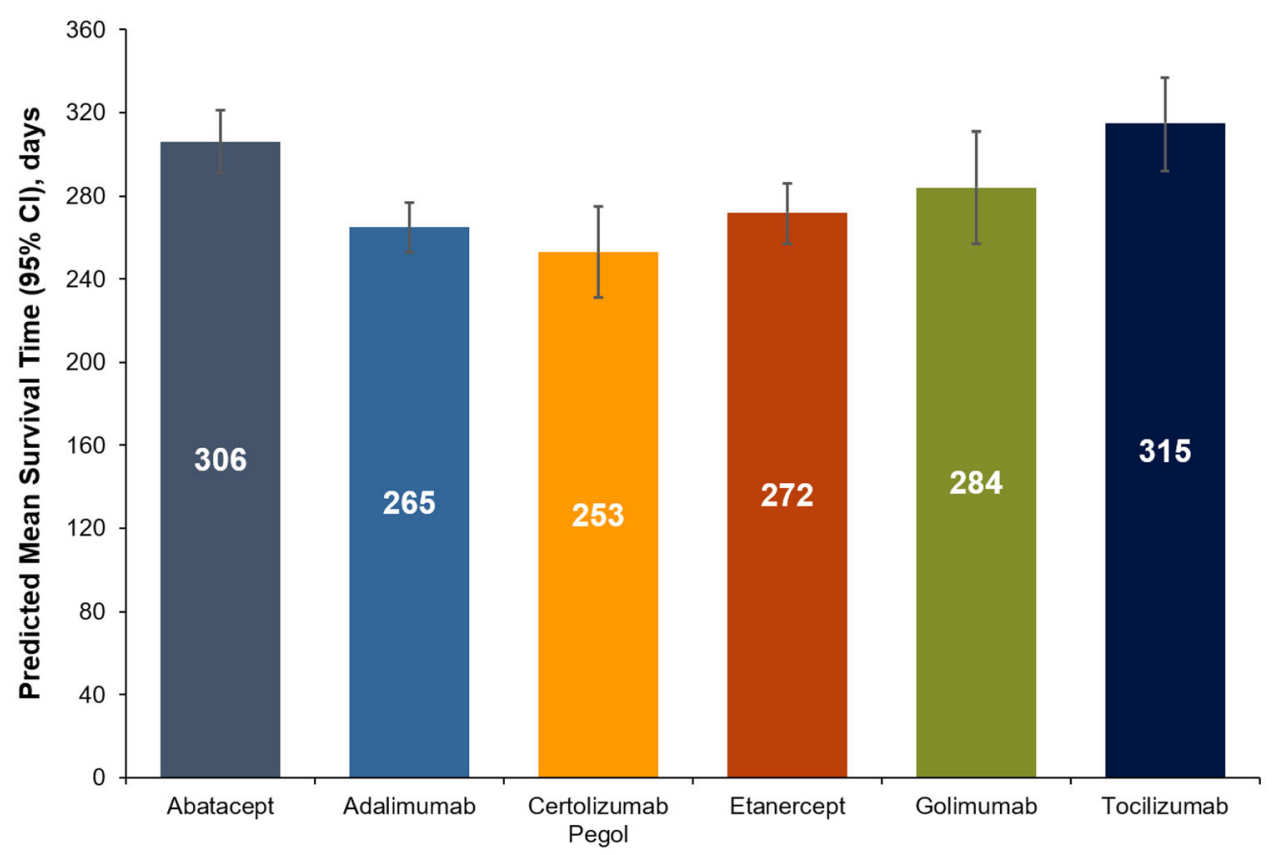

$D D M A R D$ biologic disease-modifying antirheumatic drug, $R A$ rheumatoid arthritis.

a Secondary persistence was defined as the time patients were receiving bDMARDs until they

switched or had a gap $>90$ days. The adjusted means were derived from the survival models

after adjusting for patients' baseline demographics, lines of therapy and episode specific

comorbidities

Fig. 4 Adjusted mean secondary persistence with bDMARDs among patients with RA ${ }^{a}$

Table 2 Risk of discontinuing bDMARDs vs. tocilizumab for primary persistence

\begin{tabular}{lllllll}
\hline & $\begin{array}{l}\text { Abatacept } \\
\boldsymbol{n}=\mathbf{2 9 8 8}\end{array}$ & $\begin{array}{l}\text { Adalimumab } \\
\boldsymbol{n}=\mathbf{3 5 9 9}\end{array}$ & $\begin{array}{l}\text { Certolizumab pegol } \\
\boldsymbol{n}=\mathbf{9 8 2}\end{array}$ & $\begin{array}{l}\text { Etanercept } \\
\boldsymbol{n}=\mathbf{2 7 6 0}\end{array}$ & $\begin{array}{l}\text { Golimumab } \\
\boldsymbol{n}=\mathbf{7 4 5}\end{array}$ & $\begin{array}{l}\text { Tocilizumab } \\
\boldsymbol{n}=\mathbf{1 6 3 0}\end{array}$ \\
\hline Hazard ratio & 1.04 & 1.19 & 1.27 & 1.15 & 1.10 & Reference \\
$(95 \% \mathrm{CI})^{\mathrm{a}}$ & $(0.96-1.13)$ & $(1.10-1.29)$ & $(1.14-1.41)$ & $(1.06-1.26)$ & $(0.98-1.24)$ & \\
\hline
\end{tabular}

LDMARD biologic disease-modifying antirheumatic drug

${ }^{a}$ Hazard ratios were derived from the survival models after adjusting for patients' baseline demographics, lines of therapy, and episode-specific comorbidities

Table 3 Risk of discontinuing bDMARDs vs. tocilizumab for secondary persistence

\begin{tabular}{lllllll}
\hline & $\begin{array}{l}\text { Abatacept } \\
\boldsymbol{n}=\mathbf{2 9 8 8}\end{array}$ & $\begin{array}{l}\text { Adalimumab } \\
\boldsymbol{n}=\mathbf{3 5 9 9}\end{array}$ & $\begin{array}{l}\text { Certolizumab pegol } \\
\boldsymbol{n}=\mathbf{9 8 2}\end{array}$ & $\begin{array}{l}\text { Etanercept } \\
\boldsymbol{n}=\mathbf{2 7 6 0}\end{array}$ & $\begin{array}{l}\text { Golimumab } \\
\boldsymbol{n}=\mathbf{7 4 5}\end{array}$ & $\begin{array}{l}\text { Tocilizumab } \\
\boldsymbol{n}=\mathbf{1 6 3 0}\end{array}$ \\
\hline Hazard ratio & 1.03 & 1.19 & 1.24 & 1.16 & 1.11 & Reference \\
$(95 \% \mathrm{CI})^{\mathrm{a}}$ & $(0.94-1.12)$ & $(1.09-1.29)$ & $(1.12-1.39)$ & $(1.06-1.27)$ & $(0.98-1.25)$ & \\
\hline
\end{tabular}

DDMARD biologic disease-modifying antirheumatic drug

${ }^{a}$ Hazard ratios were derived from the survival models after adjusting for patients' baseline demographics, lines of therapy, and episode-specific comorbidities 
improvements in ACR response and DAS28 remission were achieved [22]. The flexibility to increase dosing based on clinical response may contribute to the longer persistence observed with tocilizumab.

\section{Limitations}

The results of this analysis may not be generalizable to all patients with RA, including those who do not have health insurance. Drug samples provided to the patient by their doctor and prescriptions filled in situations where the patient does not use their prescription drug coverage are not captured in the pharmacy claims data in the MarketScan databases. Finally, a substantial proportion of tocilizumab use $(45.8 \%)$ was as a second-line bDMARD, but some patients also received tocilizumab as a third-line (33.3\%) or subsequent-line bDMARD. Thus, one should also consider the possibility that persistence was longer in this group of patients because fewer options for subsequent therapies were available to them. However, the analysis was adjusted for line of therapy, and an increasing number of biologic therapies are available for patients, so we do not believe that this had an effect on persistence.

Despite the abovementioned limitations, this study involving a large number of second- or subsequent-line SC bDMARD episodes in patients with RA across the United States provides valuable real-world information and adds to the existing data on persistence with bDMARDs.

\section{CONCLUSIONS}

Among patients with RA who previously received $\geq 1$ other bDMARD, those who received tocilizumab exhibited similar or significantly better persistence than those receiving other bDMARDs.

\section{ACKNOWLEDGEMENTS}

Funding. This work was funded by Genentech, Inc. All authors had full access to all data in this study and take complete responsibility for the integrity of the data and accuracy of the data analysis. The Rapid Service Fee was funded by Genentech, Inc.

Medical Writing Assistance. Support for third-party writing assistance, furnished by Nicola Gillespie, DVM, of Health Interactions, Inc., was provided by Genentech, Inc.

Authorship. All named authors meet the International Committee of Medical Journal Editors (ICMJE) criteria for authorship for this article, take responsibility for the integrity of the work as a whole, and have given their approval for this version to be published.

Authorship Contributions. All authors were involved in drafting the manuscript, reviewing, and revising it critically for important intellectual content, and all authors read and approved the final version. All authors also contributed to the study design, analysis, and interpretation of data.

Prior Presentation. A portion of these data was presented at the 2019 EULAR Annual European Congress of Rheumatology, June 12-15, Madrid, Spain, and at the 2019 ACR Annual Meeting, November 8-13, Atlanta, GA, USA.

Disclosures. Jennie H. Best, Lenore Tominna, and Ibrahim Abbass are employees of Genentech, Inc. Steven C. Vlad has received speakers bureau fees from AbbVie $(<\$ 10,000)$, consulting fees from Kiniksa, Horizon Therapeutics, AbbVie, and UCB $(<\$ 10,000)$, and research funding from Regeneron, Centrexion, AbbVie, UCB, GSK, Samumed, Galapagos NV, Eli Lilly, and Novartis.

Compliance with Ethics Guidelines. This retrospective, observational analysis used only de-identified patient records and did not include the collection, use, or transmittal of individually identifiable data; therefore, institutional review board approval to conduct this study was not necessary. 
Data Availability. The database used for the analyses in this paper is commercially available from IBM Watson at https://www.ibm.com/ watson-health/learn/truven-health-analytics. The license agreement to access these data does not give the authors permission to share this database.

Open Access. This article is licensed under a Creative Commons Attribution-NonCommercial 4.0 International License, which permits any non-commercial use, sharing, adaptation, distribution and reproduction in any medium or format, as long as you give appropriate credit to the original author(s) and the source, provide a link to the Creative Commons licence, and indicate if changes were made. The images or other third party material in this article are included in the article's Creative Commons licence, unless indicated otherwise in a credit line to the material. If material is not included in the article's Creative Commons licence and your intended use is not permitted by statutory regulation or exceeds the permitted use, you will need to obtain permission directly from the copyright holder. To view a copy of this licence, visit http://creativecommons.org/licenses/by$\mathrm{nc} / 4.0 /$.

\section{REFERENCES}

1. Smolen JS, Aletaha D, McInnes IB. Rheumatoid arthritis. Lancet. 2016;388(10055):2023-38.

2. Singh JA, Saag KG, Bridges SL Jr, et al. 2015 American College of Rheumatology guideline for the treatment of rheumatoid arthritis. Arthritis Care Res (Hoboken). 2016;68(1):1-25.

3. Smolen JS, Landewé RBM, Bijlsma JWJ, et al. EULAR recommendations for the management of rheumatoid arthritis with synthetic and biological disease-modifying antirheumatic drugs: 2019 update. Ann Rheum Dis. 2020. https://doi.org/10. 1136/annrheumdis-2019-216655.

4. Smolen JS, Breedveld FC, Burmester GR, et al. Treating rheumatoid arthritis to target: 2014 update of the recommendations of an international task force. Ann Rheum Dis. 2016;75(1):3-15.
5. Souto A, Maneiro JR, Gomez-Reino JJ. Rate of discontinuation and drug survival of biologic therapies in rheumatoid arthritis: a systematic review and meta-analysis of drug registries and health care databases. Rheumatology (Oxford). 2016;55(3): 523-34.

6. Bathon JM, Martin RW, Fleischmann RM, et al. A comparison of etanercept and methotrexate in patients with early rheumatoid arthritis. N Engl J Med. 2000;343(22):1586-93.

7. Weinblatt ME, Keystone EC, Furst DE, et al. Adalimumab, a fully human anti-tumor necrosis factor alpha monoclonal antibody, for the treatment of rheumatoid arthritis in patients taking concomitant methotrexate: the ARMADA trial. Arthritis Rheum. 2003;48(1):35-45.

8. Maini R, St Clair EW, Breedveld F, et al. Infliximab (chimeric anti-tumour necrosis factor alpha monoclonal antibody) versus placebo in rheumatoid arthritis patients receiving concomitant methotrexate: a randomised phase III trial. ATTRACT Study Group. Lancet. 1999;354(9194): 1932-9.

9. Rubbert-Roth A, Finckh A. Treatment options in patients with rheumatoid arthritis failing initial TNF inhibitor therapy: a critical review. Arthritis Res Ther. 2009;11(suppl 1):S1.

10. Chastek B, Becker LK, Chen CI, Mahajan P, Curtis JR. Outcomes of tumor necrosis factor inhibitor cycling versus switching to a disease-modifying anti-rheumatic drug with a new mechanism of action among patients with rheumatoid arthritis. J Med Econ. 2017;20(5):464-73.

11. Wei W, Knapp K, Wang L, et al. Treatment persistence and clinical outcomes of tumor necrosis factor inhibitor cycling or switching to a new mechanism of action therapy: real-world observational study of rheumatoid arthritis patients in the United States with prior tumor necrosis factor inhibitor therapy. Adv Ther. 2017;34(8):1936-52.

12. Contreras-Yanez I, Pascual-Ramos V. Window of opportunity to achieve major outcomes in early rheumatoid arthritis patients: how persistence with therapy matters. Arthritis Res Ther. 2015;17(1):177.

13. Elixhauser A, Steiner C, Harris DR, Coffey RM. Comorbidity measures for use with administrative data. Med Care. 1998;36(1):8-27.

14. van Walraven C, Austin PC, Jennings A, Quan H, Forster AJ. A modification of the Elixhauser comorbidity measures into a point system for hospital death using administrative data. Med Care. 2009;47(6):626-33. 
15. Quan H, Sundararajan V, Halfon P, Fong A, Burnand $\mathrm{B}$, Luthi JC, et al. Coding algorithms for defining comorbidities in ICD-9-CM and ICD-10 administrative data. Med Care. 2005;43(11): 1130-9.

16. Leslie RS. Calculating medication compliance, adherence, and persistence in administrative pharmacy claims databases. San Diego: MedImpact Healthcare Systems, Inc.; 2008.

17. Santos-Faria D, Tavares-Costa J, Eusebio M, et al. Tocilizumab and rituximab have similar effectiveness and are both superior to a second tumour necrosis factor inhibitor in rheumatoid arthritis patients who discontinued a first TNF inhibitor. Acta Rheumatol Port. 2019;44(2):103-13.

18. Ebina K, Hashimoto M, Yamamoto W, et al. Drug retention and discontinuation reasons between seven biologics in patients with rheumatoid arthritis-the ANSWER cohort study. PLoS One. 2018;13(3):e0194130.

19. Hishitani Y, Ogata A, Shima Y, et al. Retention of tocilizumab and anti-tumour necrosis factor drugs in the treatment of rheumatoid arthritis. Scand J Rheumatol. 2013;42(4):253-9.

20. Murage MJ, Tongbram V, Feldman SR, et al. Medication adherence and persistence in patients with rheumatoid arthritis, psoriasis, and psoriatic arthritis: a systematic literature review. Patient Prefer Adherence. 2018;12:1483-503.

21. Kremer JM, Rigby W, Singer NG, et al. Sustained response following discontinuation of methotrexate in patients with rheumatoid arthritis treated with subcutaneous tocilizumab: results from a randomized, controlled trial. Arthritis Rheumatol (Hoboken). 2018;70(8):1200-8.

22. Kivitz A, Olech E, Borofsky MA, et al. Two-year efficacy and safety of subcutaneous tocilizumab in combination with disease-modifying antirheumatic drugs including escalation to weekly dosing in rheumatoid arthritis. J Rheum. 2018;45(4):456-64.

23. Kremer JM, Blanco R, Halland AM, et al. Clinical efficacy and safety maintained up to 5 years in patients with rheumatoid arthritis treated with tocilizumab in a randomised trial. Clin Exp Rheumatol. 2016;34(4):625-33.

24. Burmester GR, Rigby WF, van Vollenhoven RF, et al. Tocilizumab combination therapy or monotherapy or methotrexate monotherapy in methotrexate-naive patients with early rheumatoid arthritis: 2-year clinical and radiographic results from the randomised, placebo-controlled FUNCTION trial. Ann Rheum Dis. 2017;76(7):1279-84.
25. Emery P, Keystone E, Tony HP, et al. IL-6 receptor inhibition with tocilizumab improves treatment outcomes in patients with rheumatoid arthritis refractory to anti-tumour necrosis factor biologicals: results from a 24-week multicentre randomised placebo-controlled trial. Ann Rheum Dis. 2008;67(11):1516-23.

26. Sullivan SD, Alfonso-Cristancho R, Carlson J, Mallya U, Ringold S. Economic consequences of sequencing biologics in rheumatoid arthritis: a systematic review. J Med Econ. 2013;16(3):391-6.

27. Bonafede MMK, McMorrow D, Proudfoot C, Shinde S, Kuznik A, Chen CI. Treatment persistence and healthcare costs among patients with rheumatoid arthritis after a change in targeted therapy. Am Health Drug Benefits. 2018;11(4):192-202.

28. Chastek B, Chen CI, Proudfoot C, Shinde S, Kuznik A, Wei W. Treatment persistence and healthcare costs among patients with rheumatoid arthritis changing biologics in the USA. Adv Ther. 2017;34(11):2422-35.

29. Cantini F, Niccoli L, Nannini C, et al. Second-line biologic therapy optimization in rheumatoid arthritis, psoriatic arthritis, and ankylosing spondylitis. Semin Arthritis Rheum. 2017;47(2): 183-92.

30. Emery P, Gottenberg JE, Rubbert-Roth A, Sarzi-Puttini P, Choquette D, Taboada VM, et al. Rituximab versus an alternative TNF inhibitor in patients with rheumatoid arthritis who failed to respond to a single previous TNF inhibitor: SWITCH-RA, a global, observational, comparative effectiveness study. Ann Rheum Dis. 2015;74(6):979-84.

31. Favalli EG, Biggioggero M, Marchesoni A, Meroni PL. Survival on treatment with second-line biologic therapy: a cohort study comparing cycling and swap strategies. Rheumatology (Oxford). 2014;53(9):1664-8.

32. Rotar Z, Hocevar A, Rebolj Kodre A, Praprotnik S, Tomsic M. Retention of the second-line biologic disease-modifying antirheumatic drugs in patients with rheumatoid arthritis failing one tumor necrosis factor alpha inhibitor: data from the BioRx.si registry. Clin Rheumatol. 2015;34(10):1787-93.

33. Harnett J, Wiederkehr D, Gerber R, Gruben D, Koenig A, Bourret J. Real-world evaluation of TNFinhibitor utilization in rheumatoid arthritis. J Med Econ. 2016;19(2):91-102.

34. Genentech, Inc. ACTEMRA prescribing information. South San Francisco: Genentech, Inc.; 2019. 